\title{
Cardiac benign tumors: echocardiography and computed tomography findings in two cases with histopathologic correlation
}

\author{
Nilda Espinola-Zavaleta $\cdot$ Jorge Delgado-Barriga • \\ Maria Virgilia Soto-Abraham • Maria Elena Soto • \\ Eulo Lupi-Herrera
}

Received: 30 March 2012/ Accepted: 16 October 2012/Published online: 20 December 2012

(C) The Japan Society of Clinical Oncology 2012

\begin{abstract}
Objectives The aim of this study is to present two patients with cardiac tumors, which by their localization, size and histopathological lineage, can be considered very rare.

Methods The clinical, echocardiographic, computed tomography and pathological findings obtained in two examples were analyzed.

Results The first case was a 54-year-old female who had progressive dyspnea with small efforts and presyncope of 1 month of evolution, most likely related to obstructive tricuspid valve myxoma-generated process, which protruded into the right ventricle reaching the apex, as was demonstrated in bidimensional color Doppler and tridimensional echocardiography. The second case was a 66-year-old male with a 6-month history of fatigue, weakness and dyspnea with great effort. The echocardiogram showed an heterogeneous ovoid mass in the right ventricle, attached to the interventricular septum with tricuspid septal leaflet infiltration. The cardiac computed tomography (CT) corroborated the presence of tumor with calcification and fat components, suggestive of teratoma,
\end{abstract}

N. Espinola-Zavaleta $\cdot$ J. Delgado-Barriga $\cdot$

M. E. Soto $(\bowtie) \cdot$ E. Lupi-Herrera

The American British Cowdray Medical Center IAP, Mexico, Mexico

e-mail: mesoto50@hotmail.com

N. Espinola-Zavaleta

e-mail: niesza2001@hotmail.com

N. Espinola-Zavaleta $\cdot$ M. V. Soto-Abraham - M. E. Soto National Institute of Cardiology "Ignacio Chavez", Mexico, Mexico

N. Espinola-Zavaleta

Peripheral South 5243, PB-A Cologne Isidro Fabela, Tlalpan, 14030 Mexico, Mexico because mature cartilage tissue is not always identifiable with CT and Hounsfield units of cartilages are variable. The calcium density on the CT image is considered to be bone or cartilage, but is not specific. The differential diagnosis with liposarcoma is described in discussion. Conclusion Two-dimensional echocardiography is the primary diagnostic imaging modality in the morphological evaluation of intracardiac masses, it is also useful in the following-up of the possible recurrences. This technique is non-invasive, low cost and provides real-time imaging with high spatial and temporal resolution. Three-dimensional echocardiography is a useful tool that provides additional information and better morphological characterization of intracardiac masses. Computed tomography can accurately identify the components of the tumor and it contributed to the proper diagnosis of teratoma. In both patients, the diagnosis was early and precise, with surgical curative resection of the tumors and good prognoses.

Keywords Myxoma - Teratoma - Echocardiography · Computed tomography $\cdot$ Surgery

\section{Introduction}

Primary heart tumors are rare, with an estimated incidence of $0.0017-0.19 \%$. Approximately $75 \%$ of these tumors are benign and about $50 \%$ of benign tumors are myxomas, and $75 \%$ of myxomas occur in the left atrium. Right atrial myxomas are rare and occur in 15-20\% of cases [1]. The low incidence of right atrial myxomas has been reported for decades in several autopsy series [2, 3]. Myxomas may have a variable clinical presentation, simulating rheumatic heart disease, mitral stenosis, Ebstein anomaly, infective endocarditis or pericarditis [4]. 

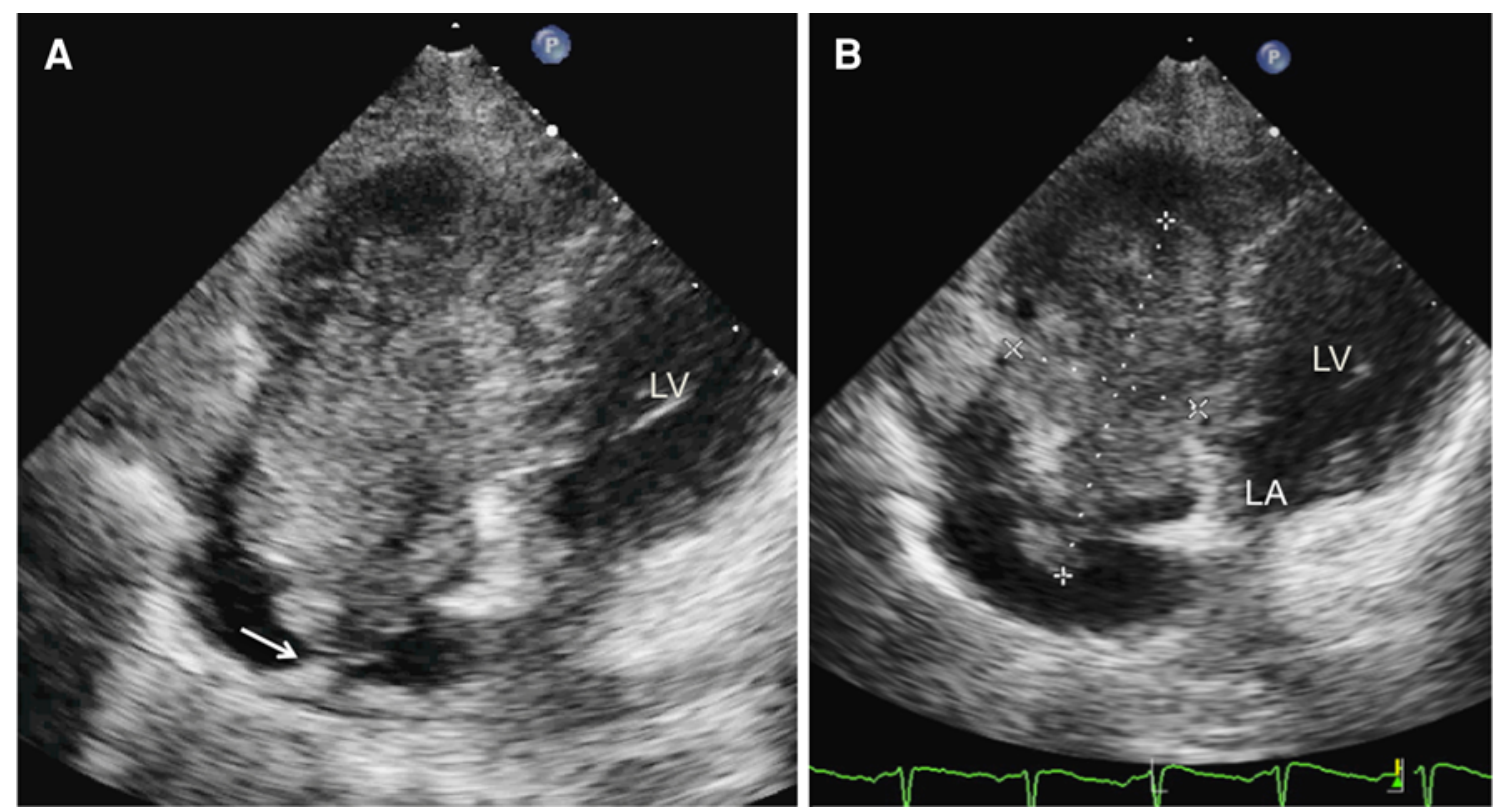

Fig. 1 Two-dimensional transthoracic echocardiogram in apical four-chamber view. a Shows a mass of heterogeneous appearance, attached to the roof of the right atrium by a short pedicle (arrow), that prolapses into the right ventricle through the tricuspid valve during diastole. $\mathbf{b}$ The size of the mass in the right cavities $(7.1 \times 3.7 \mathrm{~cm})$ is showed. $L A$ left atrium, $L V$ left ventricle
Teratomas are neoplasms containing embryonic tissue of ectodermal, mesodermal and endodermal origin. Their incidence in children is $1-15 \%$ and they may appear as myocarditis or endocardial fibroelastosis. The most frequent location is extracardiac, and only in isolated cases have they been reported in an intraventricular location [5].

The different manifestations of these tumors and lesions associated with them emphasize the importance of echocardiography and other noninvasive imaging techniques in the overall assessment of this cardiac pathology.

The aim of this study is to present two patients with cardiac tumors, which by their localization, size and histopathological lineage can be considered very rare.

\section{Case 1}

Female, 54 years old, who had symptoms of 1 month of evolution characterized by fatigue, weakness, nonproductive cough, progressive dyspnea with small efforts and presyncope. Physical examination revealed jugular venous distention grade III, rhythmic heart sounds, an audible first sound, aortic midsystolic diamond-shaped murmur 2/6, that radiates to the accessory focus, tricuspid holosystolic murmur 3/6, which increased with Rivero Carvallo maneuver, low-pitched protomeso-diastolic sound with acme in tricuspid region with intensity varying with changes in position (tumor plop). The electrocardiogram showed sinus tachycardia (120 beats/min) and right atrial enlargement. The chest radiograph was normal. The transthoracic echocardiography showed a giant mass, heterogeneous and multilobulated, irregularly shaped, with short pedicle attached to the roof of the right atrium (Fig. 1), which prolapsed through the tricuspid valve to the apex of the right ventricle and generated tricuspid valve

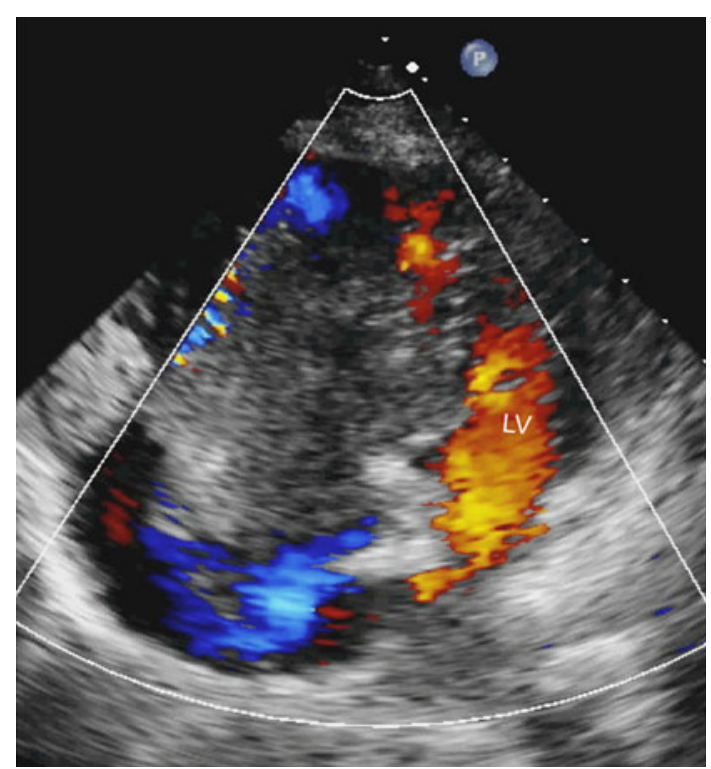

Fig. 2 Two-dimensional transthoracic echocardiography with color Doppler, showing the tricuspid valve obstruction by the mass, which prolapses through the tricuspid valve to the right ventricular apex during diastole. $L V$ left ventricle 
Fig. 3 Three-dimensional transthoracic images in fourchamber and long axis of the right cavities, showing a giant mass in the right chambers with a thick and short pedicle (arrow) attached to the roof of the right atrium, of heterogeneous appearance and irregular contour. $L A$ left atrium, $L V$ left ventricle
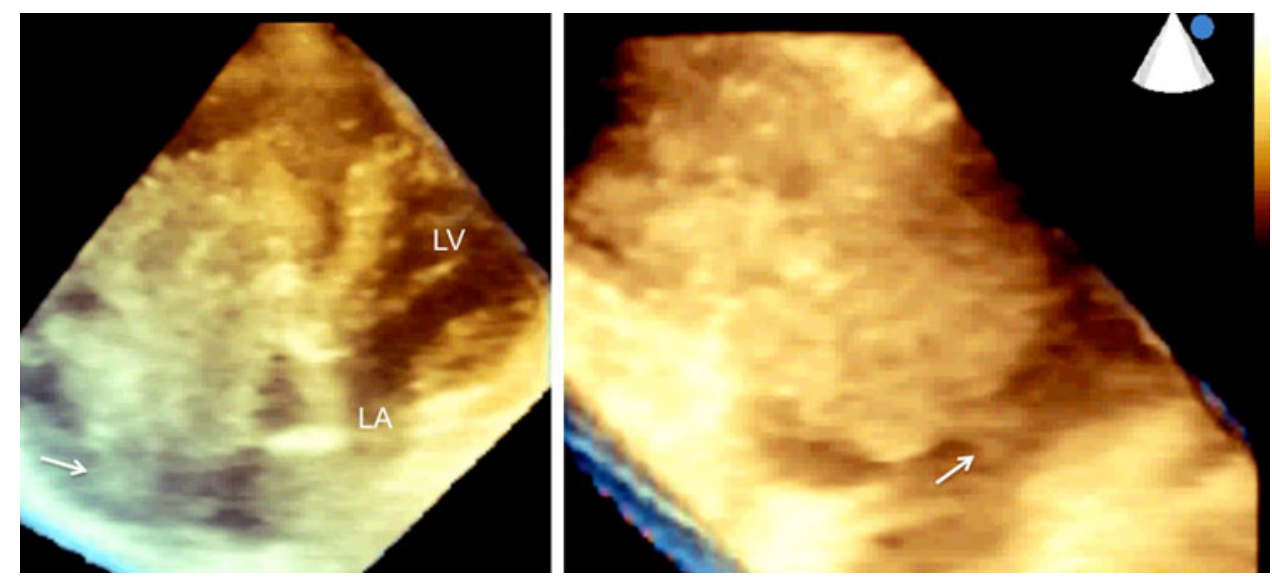

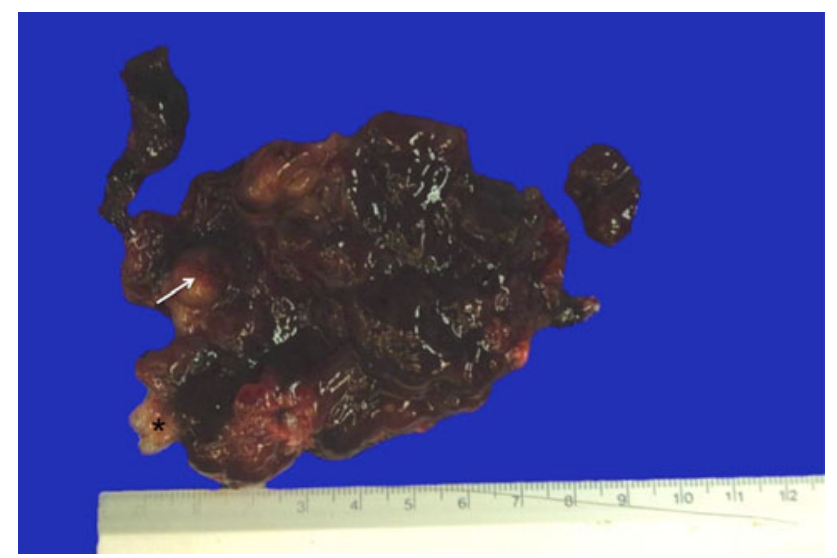

Fig. 4 Mass multinodular, light brown, of hemorrhagic appearance with areas of myxoid appearance (arrow) and short pedicle (asterisk)

obstruction in color Doppler echocardiography (Fig. 2). With the support of 3D echocardiography, a better definition of the morphological characteristics of the tumor and the pedicle (Fig. 3) was obtained. The left ventricular systolic function was preserved and diastolic dysfunction type I was found. Surgical resection of the tumor and the pedicle was performed. A tumor of $10.5 \times 7 \times 5 \mathrm{~cm}$ weighing $65 \mathrm{~g}$ was found (Fig. 4). The histopathological report was myxoma (Fig. 5).

Currently the patient is in NYHA functional class I, and without data suggestive of Carney complex.

\section{Case 2}

Male, 66 years old, with a history of facial paralysis, systemic arterial hypertension and smoking. Six months before he initiated with fatigue, weakness and dyspnea on great effort. On physical examination, precordium with apical impulse in the left fifth intercostal space on the midclavicular line was found. The heart sounds were rhythmic with physiological splitting of second sound, no murmurs and no rub were heard. The electrocardiogram was in sinus rhythm with HR of 58 beats/min, within normal parameters and normal chest radiograph without cardiomegaly (ICT-0.48). The transthoracic echocardiogram showed ovoid mass of heterogeneous appearance of $4 \times 3 \mathrm{~cm}$ of diameter in the right ventricle, attached to the interventricular septum (Fig. 6). Transesophageal echocardiography confirmed the presence of mass in the right ventricle and also showed an infiltration of the tricuspid septal leaflet by the tumor (Fig. 7). The cardiac computed tomography showed a right intraventricular tumor of $4 \times 3.5 \mathrm{~cm}$ diameter attached to the interventricular septum with calcification and components suggestive of a teratoma (Fig. 8). Cardiac catheterization showed no coronary lesions. The bone scan was normal.

Resection of the right ventricular ovoid tumor that measured $4.5 \times 4.1 \times 4 \mathrm{~cm}$, with irregular outer surface, multinodular, greyish brown (Fig. 9) was done. By cutting, the lesion is heterogeneous with solid zones, rubbery and tough consistency with cystic areas alternating with mucous material in its interior. Histopathological examination showed a solid mature teratoma (Fig. 10). A tricuspid INC no. 28 bioprosthesis was implanted.

Actually, the patient is in functional class I of NYHA. The control echocardiogram revealed a tricuspid bioprosthesis normally functioning.

\section{Discussion}

Primary cardiac tumors occur most frequently in the third to sixth decade of life, there are more common in women and represent $<5 \%$ of all cardiac tumors. The majority of these tumors are benign, but the incidence of malignancy ranges from 10-50\% in infants and increases with age.

The two cases presented can be considered rare. In the first, the size, we note the unusual location and symptomatology with progressive dyspnea even with small efforts, 

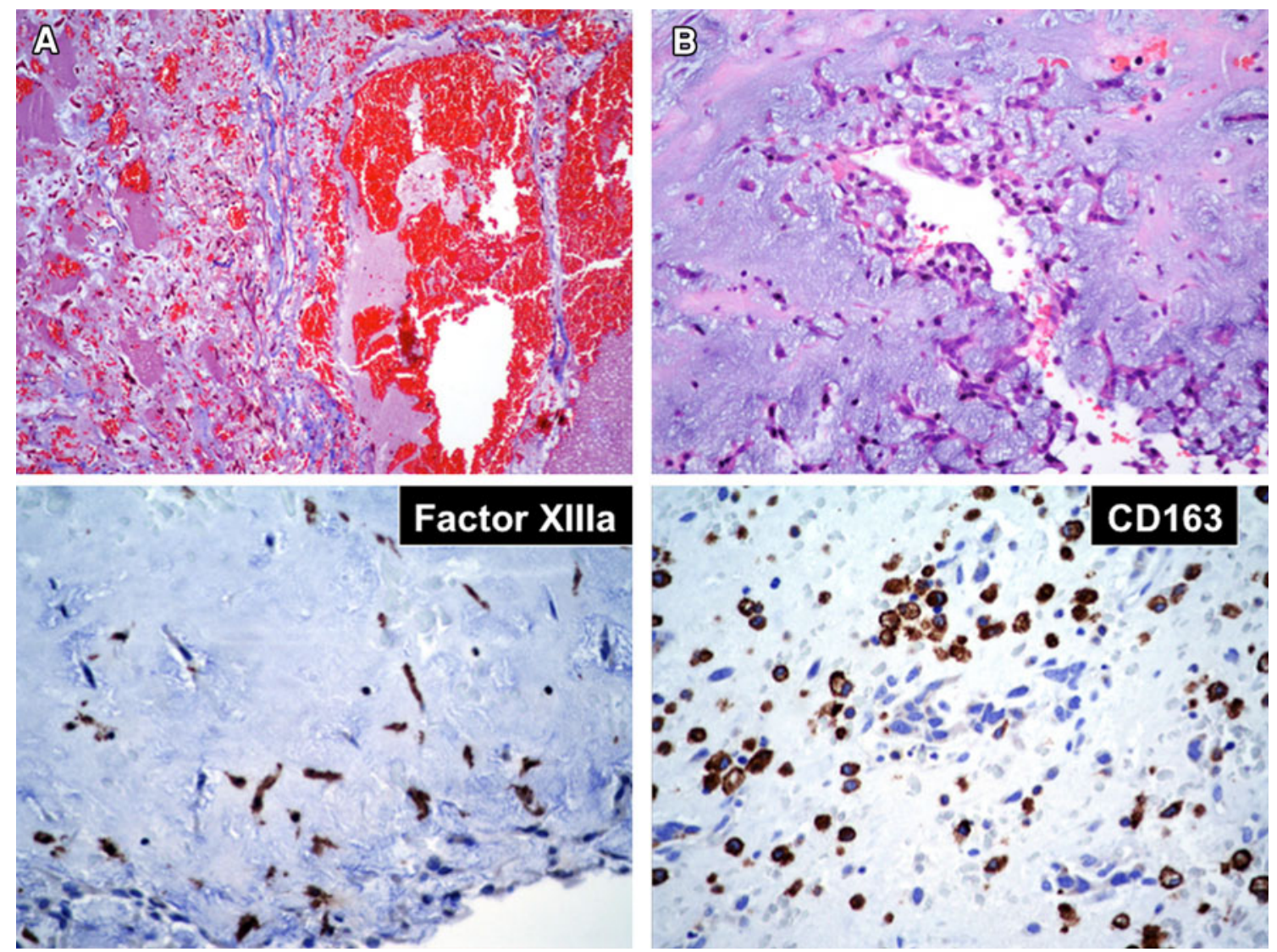

Fig. 5 Neoplastic lesion groups formed by star-shaped cells in a myxoid stroma (a) which are arranged around lights of vascular aspect (b) positive for Factor XIIIa and CD163

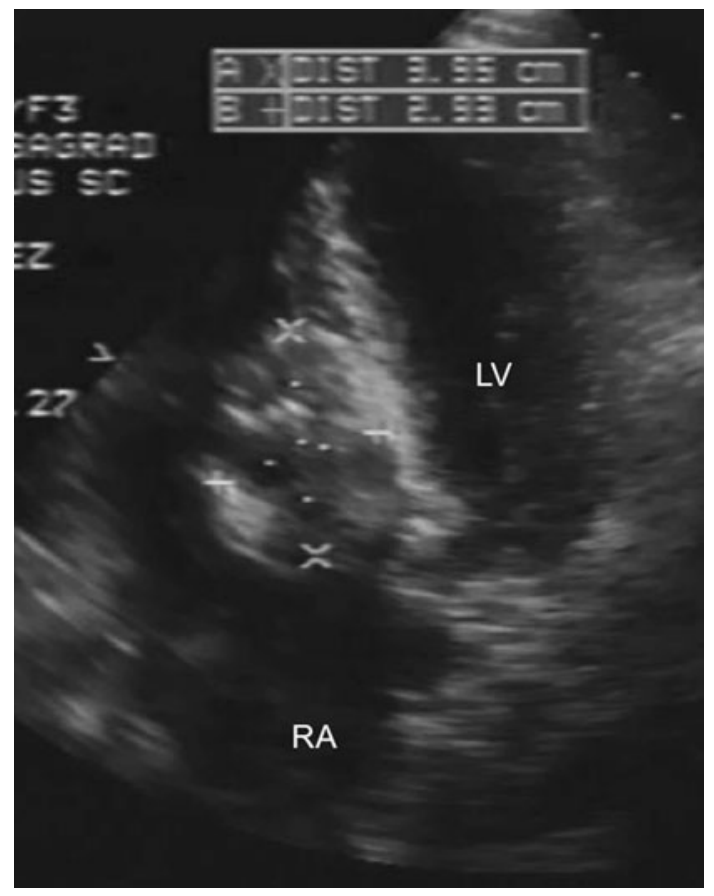

Fig. 6 Heterogeneous mass of ovoid appearance, attached to the interventricular septum, growing to the right ventricle with diameters of $4 \times 3 \mathrm{~cm} . L V$ left ventricle, $R A$ right atrium most likely related to obstructive tricuspid valve myxomagenerated process, which protruded into the right ventricle reaching the apex, as it was demonstrated in color Doppler echocardiography. In the literature, there are only two cases: one women of 39 years old [6] and the other one of 74 years old [7] with tricuspid valve obstruction provoked by a giant right atrial myxoma.

Right atrial myxomas may remain asymptomatic [8] or eventually cause constitutional and circulatory symptoms [1]. The latter may be due to secretion of vasoactive products or autoimmune response to myxoma tumor products or production of cytokines such as interleukin 6 [9]. In cases of right atrial myxoma, pulmonary embolism can occur between 2 and $24 \%$ of patients by detached tumor fragments or thrombi from the tumor surface and present with dyspnea, chest pain, hemoptysis, syncope, congestive right heart or even death [10]. Less frequently, tricuspid valve obstruction may occur, resulting in dyspnea, syncope or sudden death $[6,7,11]$.

In this patient despite the fact that early diagnosis and surgical treatment was successful, it is necessary to take into account the possible recurrence of the myxoma, which occurs in $8 \%$. This eventuality can be associated with 


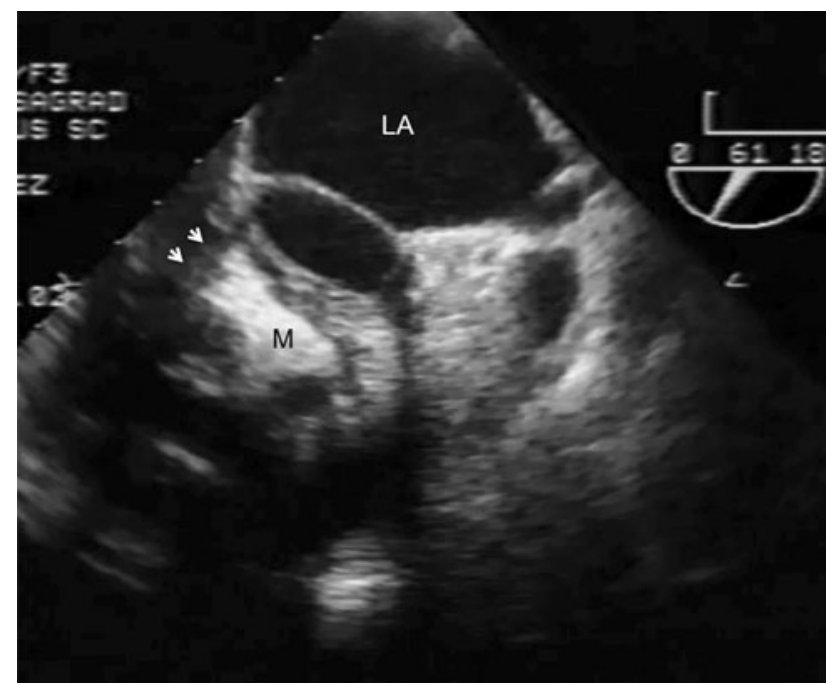

Fig. 7 Transesophageal echocardiogram at $61^{\circ}$ which confirms the presence of mass $(M)$ attached to the right side of the interventricular septum with infiltration of the tricuspid septal leaflet (head arrows) (LA left atrium)

changes in skin pigmentation and endocrine hyperactivity, abnormalities referred to Carney complex [12,13]. Medical monitoring and echocardiography is mandatory in order to identify promptly any recurrence of the myxoma.

The second case is even rarer for the following reasons: (a) the histopathological lineage, which corresponded to a benign teratoma in an adult subject and (b) its intracardiac localization, attached to the interventricular septum growing to the right ventricle and infiltration of the tricuspid septal leaflet. The most common site of teratomas is in the pericardium, attached to the base of the aortic root or

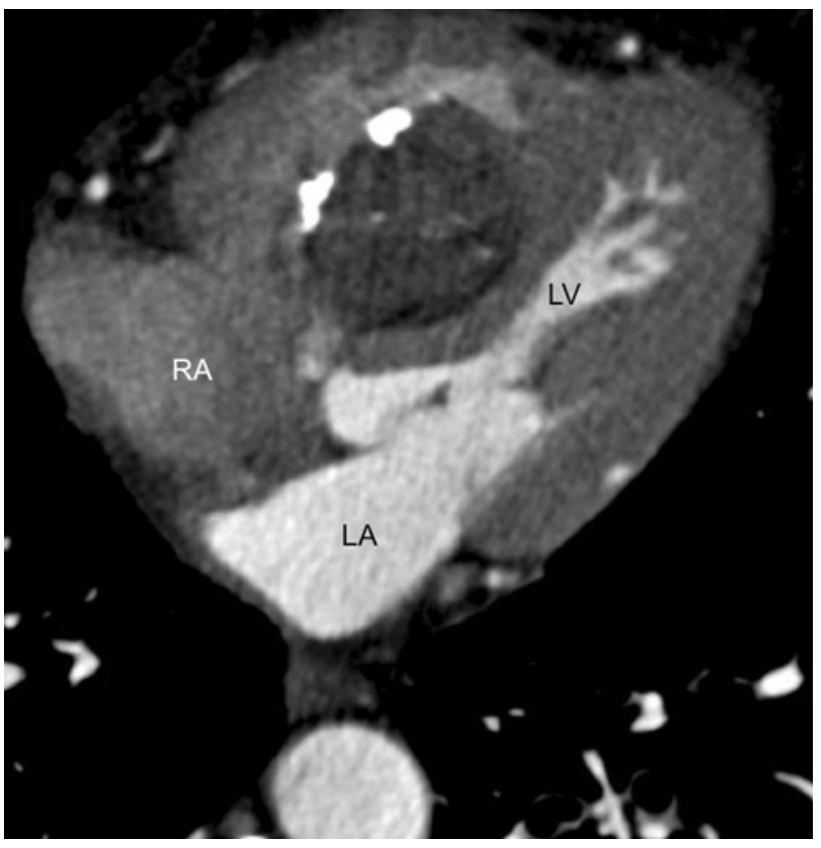

Fig. 8 The CT scan showed a right intraventricular tumor of $4 \times 3.5 \mathrm{~cm}$, attached to the interventricular septum with calcium and fat component. $L A$ left atrium, $L V$ left ventricle, $R A$ right atrium

pulmonary artery [14, 15]. Intracardiac localization is very rare, and when it occurs it is mainly in children and females $[16,17]$. As far as we know, this is the first report in the literature of a benign intracardiac teratoma, which occurs in males and in the seventh decade of life.

Echocardiography has become since its conception in the mid-1950s, the standard diagnosis technique of cardiac tumors, that allows to determine the localization,
Fig. 9 Lesion well defined with an outer surface (a) irregular and cut (b) shows solid areas alternating with cysts with mucous material in its interior
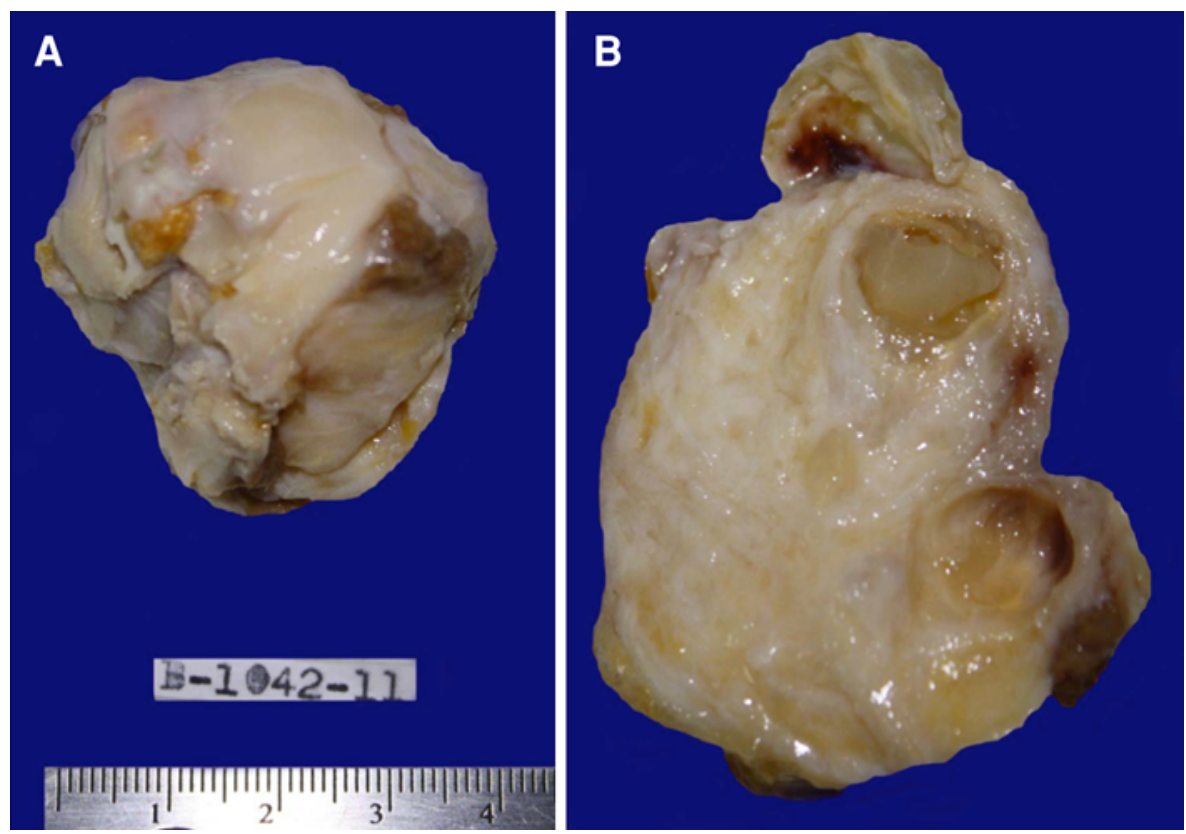

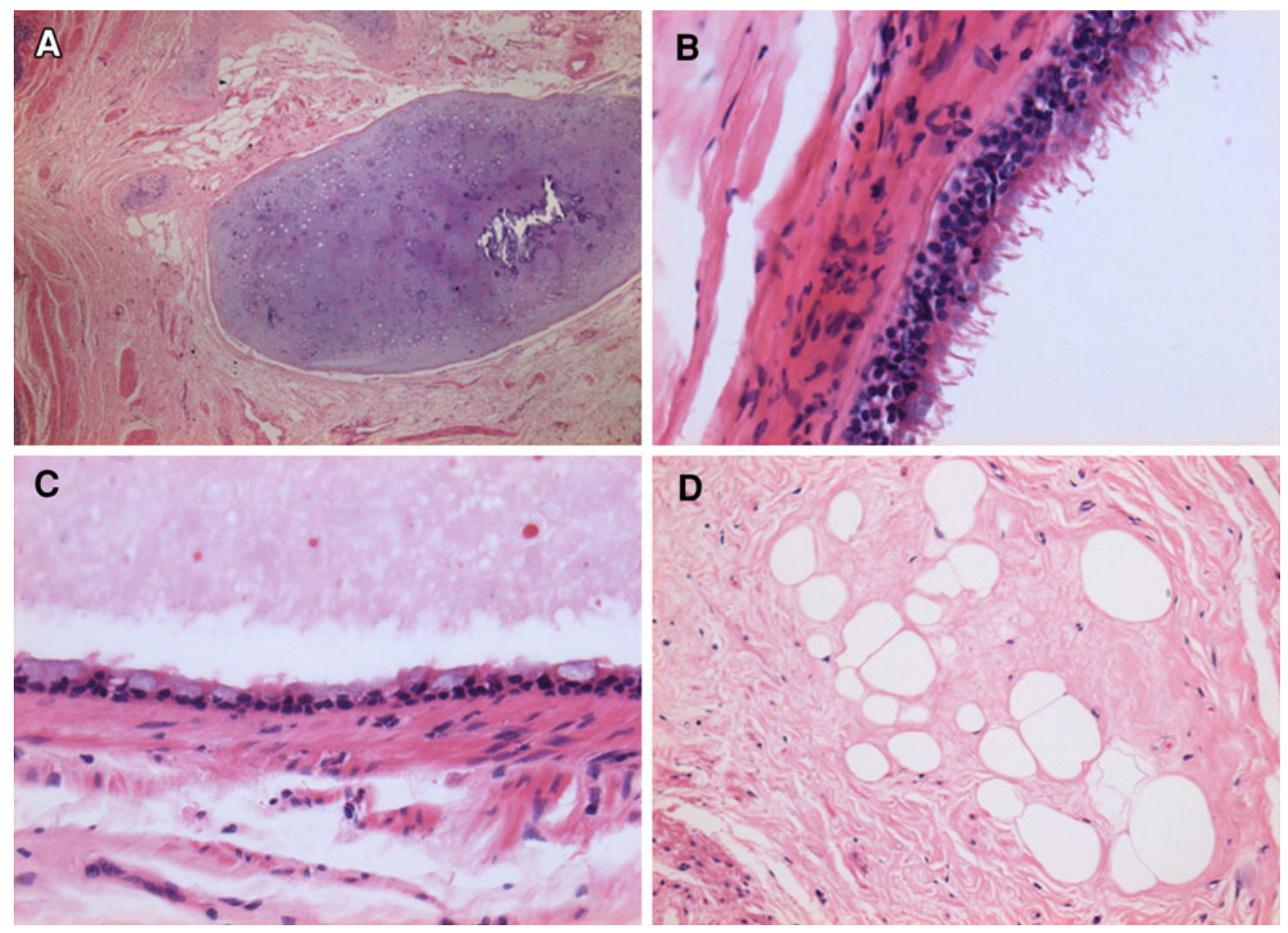

Fig. 10 Microscopic appearance of fat-containing cyst mature teratoma, there are several mature cartilage tissue (a), cystic lesions lined by respiratory epithelium (b), others with mucosecretor epithelium (c) and histologic image of fat (d)

morphology, hemodynamic repercussion and the possible involvement of adjacent structures, and establish the differential diagnosis $[7,18,18,19]$.

Although two-dimensional echocardiography provides adequate morphological characterization of intracardiac masses, transthoracic three-dimensional echocardiography is superior for surgery planning, allowing a better definition of contour and morphology of the mass, position and attachment in the interatrial septum [7] or in the roof of the right atrium as occurred in one of our patients. In some subjects it is necessary to use other imaging techniques to better define the morphology of intracardiac masses. In one of our cases, computed tomography nicely demonstrated the fat component (areas with very low Hounsfield values) and calcification (corresponding to bone or cartilage), and it contributed to the proper diagnosis of teratoma. Liposarcoma may be listed in the differential diagnosis of a fat-containing mass. Liposarcoma is a malignant mesenchymal tumor, which most often occurs in the fifth and sixth decades [20]. The amount of identifiable fat by $\mathrm{CT}$ in liposarcoma varies widely and it shows moderately low attenuation ( -10 or less HU).

The clinical, echocardiographic, computed tomography and pathological findings obtained in these examples were critical to the success of surgical treatment and to lay the foundations of the prognosis [21, 22]. Currently, after 8 months and 4 months follow-up, respectively, our patients are in NYHA functional class I, without evidence of recurrence or in case of prosthetic dysfunction.

\section{Conclusion}

The two-dimensional echocardiography is the primary diagnostic imaging modality in the morphological evaluation of intracardiac masses, it is also useful in the following-up the possible recurrences. This technique is non-invasive, low cost and provides real-time imaging with high spatial and temporal resolution. The three-dimensional echocardiography is a useful tool that provides additional information and better morphological characterization of intracardiac masses. Computed tomography can accurately identify the components of the tumor and it contributed to the proper diagnosis of teratoma.

In both patients, the diagnosis was timely and accurate, with surgical curative resection of the tumors and good prognosis. Patients have been reported in the literature with 
myxomas that presented at sudden death because a timely diagnosis was not made.

Conflict of interest The authors declare that they have no conflict of interest.

\section{References}

1. Reynen K (1995) Cardiac myxomas. N Engl J Med 333:1610-1617

2. Wold LE, Lie JT (1980) Cardiac myxomas. A clinicopathological profile. Am J Pathol 101:219-233

3. Yu K, Liu Y, Wang H, Hu S, Long C (2007) Epidemiological and pathological characteristics of cardiac tumors: a clinical study of 242 cases. Interact Cardiovasc Thorac Surg 6:636-639

4. Yuste P, Asin E, Cerdan FJ, Fuente A (1976) Right atrial myxoma in echocardiogram. Chest 69:94-96

5. Cox JN, Fnedli B, Mechmeche R, Ben lsmmail M, Oberhaensli I, Faidutti B (1983) Teratoma of the heart. Arch Pathol Anat 402:163-174

6. Bilku RS, Loubani M, Been M, Patel RL (2008) Massive right atrial myxoma causing exertional dyspnoea. Eur J Echocardiogr 9:130-132

7. Azevedo O, Almeida J, Nolasco T et al (2010) Massive right atrial myxoma as syncope and exertional dysnea: case report. Cardiovasc Ultrasound 8:23

8. Yuce M, Dagdelen S, Ergelen M, Eren N, Caglar N (2007) A huge obstructive myxoma located in the right heart without causing any symptom. Int J Cardiol 114:405-406

9. Kanda T, Umeyama S, Sasaki S et al (1994) Interleukin-6 and cardiac myxoma. Am J Cardiol 74:965-967

10. Alsafwah S, Lababidi Z (2001) Recurrent pulmonary embolism originating from right atrial myxoma. J Am Soc Echocardiogr 14:305-307
11. Surabhi SK, Fasseas P, VanDecker WA, Hanau CA, Wolf NM (2001) Right atrial myxoma in a patient presenting with syncope. Tex Heart Inst J 28:228-229

12. Vargas-Barron J, Vargas-Alarcon G, Roldan FJ et al (2008) A cardiac myxomas and the Carney complex. Rev Esp Cardiol 61:1205-1209

13. Carney JA, Gordon H, Carpenter PC, Shenoy BV, Go VL (1985) The complex of myxomas, spotty pigmentation, and endocrine overactivity. Medicine 64:270-283

14. Tolles T, Casselman P, Devlieguer H et al (1998) Fetal cardiac tamponade due to an intrapericardial teratoma. Ann Thorac Surg 66:559-560

15. Morales-Quispe JA, Rebollar-Dominguez A, Caballero-Caballero $\mathrm{R}$ et al (2011) Neonatal intrapericardial teratoma stage: diagnosis and evolution. Arch Cardiol Mex 81:22-25

16. Kanjuh V, Zecevic DS, Cemerlic NA, Rafajlovski S, Novakovic A (2008) Benign tumors of the heart. Scr Med 1(Suppl 2):153

17. Costas C, Williams RL, Fortune RL (1986) Intracardiac teratoma in an infant. Pediatr Cardiol 7:179-181

18. Yuan SM, Shinfeld A, Lavee J, Kuperstein R, Haizler R, Raanani E (2009) Imaging morphology of cardiac tumours. Cardiol J $16: 26-35$

19. Shapiro LM (2001) Cardiac tumours: diagnosis and management. Heart 85:218-222

20. Lahta G, Madewell JE, Anaya DA, Tuvin D, Benjamin RS, Lev DC, Pollock RE (2009) Computed tomography scan-driven selection of treatment for retroperitoneal liposarcoma histologic subtypes. Cancer 115:1081-1090

21. Selvaraj A, Kumar R, Ravikumar E (1999) Surgical management of right atrial myxomas: a 15 year experience with review of the literature. J Cardiovasc Surg 40:101-105

22. Roy F, Sievers B, Augustine T et al (2000) Complete surgical resection of intrapericardial teratoma in a neonate with compression of the main airways. Cardiol Young 10:64-66 